\title{
Intimately Old: From an Embodied to Emplaced Feminist Approach to Aging
}

\author{
Jessica Finlay \\ Institute for Social Research, University of Michigan, 426 Thompson Street, Ann Arbor, Michigan 48104, USA \\ Corresponding author. Email: jmfinlay@umich.edu
}

(Received 22 October 2018; revised 30 December 2019; accepted 6 February 2020)

\begin{abstract}
Aging transcends and intersects all structured social differences as a fluid complex of positionalities: a temporal situatedness in relation to gender, class, race, and sexuality. Age's operation as an organizing principle of power remains undertheorized in feminist philosophy. This article employs a geographical lens to spatialize feminist thought on old age to enrich understanding of factors underpinning expectations and practices of what particular bodies can and should do in particular spaces. Vignettes from twelve months of ethnographic fieldwork with six older individuals in a midwestern American city demonstrate the utility of advancing not just an embodied feminist philosophy of aging, but one that is emplaced to deepen understanding of the body as situated in time and space. A person's situatedness in dynamic place-events, ranging from daily life at home and engagement in supportive social spaces to experiences of discrimination and even inclement weather, produce distinct ways of being old. Investigating intimate geographies of later life from the micro to macro scale can help destabilize and challenge the objectification, control, and Othering of old people, the majority of whom are female. This article contributes greater "body a-where-ness" to feminist philosophy and stimulates novel investigation into the spatiotemporal situatedness of later life.
\end{abstract}

We all grow old. Yet we do so at different times and rates, and in distinct places and unique ways. Aging is both universal and inherently heterogeneous: it transcends and intersects all structured social differences. It is not a rigid or frozen essential identity. Rather, it represents a fluid complex of positionalities: a temporal situatedness in relation to gender, class, race, and sexuality (Loe 2011). Age operates as an organizing principle of power, yet it is rarely the explicit focus in the feminist canon. Gerontophobia shelters problematic silences regarding the ideologies and practices that shape our bodies and structure life from birth to death (Twigg 2004; Marshall 2006). This constrains theorizations of power and inequality by considering a limited set of bodies, periods of the lifespan, and geographical spaces.

To our detriment, we are far too comfortable pushing old age to the periphery in our personal and professional lives. A feminist gerontology emerged in the late 1990s and

\footnotetext{
(c) The Author(s), 2021. Published by Cambridge University Press on behalf of Hypatia, a Nonprofit Corporation. This is an Open Access article, distributed under the terms of the Creative Commons Attribution licence (http://creativecommons. org/licenses/by/4.0/), which permits unrestricted re-use, distribution, and reproduction in any medium, provided the original work is properly cited.
} 
early 2000s that drew upon personal perspectives of female scholars as they endeavored to make sense of their own and others' experiences. This scholarship resonates with themes of age oppression and social stigmatization, including the National Women's Studies Association's "Age and Ageism" issue edited by Leni Marshall (Marshall 2006). Margaret Cruikshank, Toni Calasanti and Kathleen Slevin, Margaret Gullette, Linn Sandberg, Lynne Segal, and Kathleen Woodward exemplify valuable voices in the small field bridging feminism and gerontology (Woodward 1999; Gullette 2004; Calasanti and Slevin 2006; Cruikshank 2009; Sandberg 2011; Segal 2013). This scholarship advances theories of embodiment by challenging the foundations of biological determinism and unpacking how aging is socially constructed through beliefs, customs, traditions, norms, and expectations. Aging represents a dynamic process: a matter of degree (similar to being fat) rather than a fixed identity (Segal 2013). Scholars critically identify instances of ageism including fearful disparagement of old age, the dominant feeble/frail role, and neoliberal imperatives of activity and responsibility. The field advances conceptions of aging beyond binary thinking of decline or success.

Instead of seeing "the elderly" as one homogeneous group, this scholarship considers the dynamic interplay of class, race, ethnicity, and gender that produces distinct experiences of becoming old. The multidimensional approach thus resists the all-encompassing category of "old" that places a strong emphasis on bodily difference from others. By situating aging as a sociopolitical and performative phenomenon (Calasanti and Slevin 2006; Sandberg 2011; 2013), this scholarship generates novel theoretical ideas for empowerment that translate into opportunities for greater visibility, inclusion, love, sex, care, and positive narratives of self.

In parallel to feminist gerontology, geographers have applied a feminist lens to extend beyond static and rigid understandings of old age. This includes recognition of aging and old age as influenced by culture and underpinned by a range of socioeconomic and political processes, lived experiences, and spatial practices (Hopkins and Pain 2007). Caregiving, the body, home, and emotion are key themes (for example, Mowl, Pain, and Talbot 2000; England and Dyck 2011; Herron and Skinner 2012; 2013). Although most literature concentrates on women, men are increasingly in focus through studies on embodied and emotional masculinities of aging, including grandfathers (Tarrant 2013; 2015) and older gay men (Pilkey 2013). Emerging work investigates aging as embodied, emotional, and relational (Milligan and Tarrant 2018) across a diversity of experiences and situations.

Although there is rich work on aging as embodied, analyses situating the body's biological materiality and sociocultural representations (Sandberg 2011; 2013) within dynamic ecological contexts remains limited. This article introduces novel theorization of aging as emplaced to generate greater "body a-where-ness" (Thrift 2008, 126) through a spatiotemporal mode of thinking. To illustrate the theory of emplacement, Sarah Pink rethinks the performance of Spanish bullfighting through this lens. Upon entering the arena-with sand underfoot, the hot sun beating down, and the cheers of the crowdthe bullfighters "feel" different: "They have become part of a specific configuration, or ecology, of persons and things. Their experiences are not simply embodied, but part of a unique environment in progress which both shapes and is shaped by their actions" (Pink 2011, 344). The body in sporting events does not simply provide embodied knowing and skills to act; rather, the body itself is physically transformed as part of the process. Bullfighters in Pink's work hone their physique through rigorous training and frequent performances, and are physically scarred from bullfights. The arena they perform in represents an entanglement of environmental components including animals, 
people, buildings, and the weather. It composes a complex ecology of social, material, affective, and sensory environmental processes including tastes, smells, and sounds. Furthermore, each bullfight is distinct. As a place-event, the bullfight is reconstituted each time through different processes, emotions, sensations, persons, and narratives (Massey 2005). The convergence of these elements produces different intensities of activity that are experienced by human subjects from specific subjectivities (Pink 2011). The performance of bullfighting-and performances more broadly-are thus much more than embodied. They can be interpreted as part of complex ecologies of things embedded together through time.

As Tim Ingold notes, "the world is not ready-made for life to occupy" (Ingold 2000, 242). Place represents the temporary coming together of human and nonhuman threads. This article advances theorization of aging through the spatiotemporal lens of emplacement. It demonstrates how everyday experiences and navigations of later life are contingent on mundane place-events. Environments contribute to aging in very particular ways, in which older bodies literally express structured advantages and disadvantages of surrounding past to present contexts. Older adults can in turn shape their environments and exercise agency to apply knowledges and skills to their surrounding contexts. Aging is always part of an ecology of things in progress. Attending to the reciprocal relationship between people and place enhances knowledge of complexities and ambiguities of everyday life. It generates opportunities to identify and challenge injustices, marginalization, and Othering that too often accompany old age. This article aims to motivate a breadth of feminist scholars to substantively engage with and ask vital questions about old age through a spatiotemporal lens.

\section{STUDY DESIGN: AN ETHNOGRAPHIC APPROACH}

Vignettes from six older people living in Minneapolis, Minnesota provide detailed accounts of emplaced later life. The project set out to examine how older adults negotiate and enact aging within the contexts of their everyday lives and pursue well-being through aging in place. The purposive design of three case-study areas across the Minneapolis metropolitan area selected for sociodemographic and geographic variability (methods described in detail in Finlay 2017; Finlay and Bowman 2017; Finlay 2018; Finlay and Kobayashi 2018; Finlay et al. 2019; Finlay, Gaugler, and Kane 2020). Potential participants volunteered in response to project flyers and advertisements placed in senior centers, gyms, community centers, coffee shops, sites of worship, residential buildings, and health clinics. Eligibility criteria included being over the age of 55 , not institutionalized in a care setting, residence in a case-study area, and demonstrated cognitive capacity to participate. Semi-structured seated and mobile interviews were conducted with 125 older adults from June to October 2015. The interview sessions were intense, but relatively brief, two- to four-hour snapshots into participants' lives. Ethnography provided an intimate method to better understand experiences and perspectives through broader spatial and temporal scales.

Six participants engaged in ethnographic sessions over twelve months (September 2015 to August 2016). They were purposely selected to represent a variety of socioeconomic backgrounds, health statuses, and locations. The ethnographic participants resided across all three case-study areas (Table 1). In downtown Minneapolis, Ellen (73 years) lived alone in a comfortable condominium along the river. Frank (77 years) resided alone at the other end of downtown in a subsidized high-rise. June (66 years) and Christina (78 years) both resided in older houses in North Minneapolis 
Table 1. Ethnographic study participants $(n=6)$

\begin{tabular}{|c|c|c|c|c|c|c|c|c|}
\hline Participant & Age & Gender & Race & Education & Employment (Career) & Marital Status & Driving & Residence \\
\hline Christina & 78 years & Female & $\begin{array}{l}\text { African } \\
\text { American }\end{array}$ & Bachelor's degree & $\begin{array}{l}\text { Retired (Office/ } \\
\text { managerial) }\end{array}$ & Widowed & Yes & House, North Minneapolis \\
\hline Denise & 72 years & Female & White & High school diploma & Retired (Sales) & Divorced & No & $\begin{array}{l}\text { Subsidized apartment, } \\
\text { Eden Prairie }\end{array}$ \\
\hline Ellen & 73 years & Female & White & Graduate degree & Retired (Professional) & Widowed & Yes & $\begin{array}{l}\text { Condominium, } \\
\text { Downtown Minneapolis }\end{array}$ \\
\hline Frank & 77 years & Male & White & High school diploma & Working (Service) & $\begin{array}{l}\text { Single } \\
\quad \text { (never married) }\end{array}$ & No & $\begin{array}{l}\text { Subsidized apartment, } \\
\text { Downtown Minneapolis }\end{array}$ \\
\hline June & 66 years & Female & $\begin{array}{l}\text { African } \\
\text { American }\end{array}$ & High school diploma & Retired (Service) & Widowed & No & House, North Minneapolis \\
\hline Thomas & 67 years & Male & White & Bachelor's degree & Retired (Professional) & Married & Yes & House, Eden Prairie \\
\hline
\end{tabular}


(the inner city). June lived with family members, and Christina resided alone with her dog. In the suburb of Eden Prairie, Thomas (67 years) resided in a house they'd lived in for a long time with his wife and numerous pets, and Denise (72 years) lived alone in a subsidized apartment building. June and Christina were African American; Frank, Ellen, Thomas, and Denise identified as white. All participants were retired except for Frank, who worked a janitorial night shift in order to "keep the lights on" at home. Ellen, Christina, and Thomas each owned a car and drove; Frank, June, and Denise relied on public transport, friends, and family for rides.

The ethnographic approach captured individual lived experiences nested within broader societal and cultural contexts (Marshall and Rossman 2016). I typically began with extended tours of participants' living spaces, sharing food and drink, and looking at pictures of family members. As we became better acquainted, I asked to accompany participants to places outside the home that were fixtures in their everyday lives and routines, including grocery stores, senior centers, cultural events, coffee shops, faith services, medical offices, and parks. We shopped, cooked, exercised, completed household chores, took care of grandchildren, socialized with friends and family, and engaged in lengthy conversations. In this manner, we became intimately familiar. I visited participants at least once a month (some much more frequently), and we conversed often between sessions by phone and email. Through this intimacy I was better able to understand the nuances of their lives, attitudes, and circumstances (Loe 2011; Degnen 2012).

I sought personal accounts of significant events, perceptions, and contexts as determined by participants in their own words (Dunn 2005). This approximated to normal conversational interactions and gave participants ample scope to direct our interactions. I did not use an audio recorder, but frequently wrote notes in a small notebook while we talked and took photos during some of our activities together. Following all interactions (including impromptu calls), I recorded reflections in my digital journal. This included detailed recall of events as well as my hunches, evolving understandings, concerns, positionality, expectations, and motives (Crang and Cook 1995).

I organized all photographs and field notes using the software package NVivo (Version 11) and applied a phenomenological approach to explore, describe, and analyze the meaning of individual lived experience: "how they perceive it, describe it, feel about it, judge it, remember it, make sense of it, and talk about it with others" (Patton $2002,104)$. Analyses focused on tracing the unevenness of participant well-being and their varying abilities to pursue ways of being old that were suited to them through space and over time. Member-checking (informally testing my interpretations with participants themselves); regular debriefing with research assistants, mentors, and peers; and audit trails enhanced transparency and credibility (Marshall and Rossman 2016). The study was approved by the University of Minnesota's Institutional Review Board.

This article looks to older adults themselves to depict the realities of aging. Mundane experiences and contexts of aging are often lost in medical and social-science research on later life. I purposely invert this relationship, in a similar manner to Catherine Degnen's detailed ethnographic work (Degnen 2012), to ask what can be learned about old age by attending to the fine-grained and multiple ways in which aging is negotiated and navigated in the public and private spheres of life. I am interested in the perspectives and experiences of these six individuals inhabiting a particular historical moment and built, sociocultural, natural, political, and economic contexts. Through the theoretical lens of emplacement, I investigate the processes through which their aging selves are affected and transformed by the intensities of place-events (Alidoust, Bosman, and Holden 2018). The specificities and strengths of contextual pressures 
nested together, such as home layout, access to services, racial discrimination, the weather, and interpersonal relationships, shape distinct ways of being old. Everyday navigations of aging bound up in these dynamic ecologies are fluid and reconstituted over time.

Each ethnographic participant self-identified as an older adult, but no one was over the age of 78. Thus, experiences of navigating one's eighties, nineties, and beyond are missing from the article. Scholars distinguish between the Third Age, which is viewed as having opportunities for personal growth and development, and the Fourth Age, which is seen as a black hole that cannot be fully understood and from which there is no return (Gilleard and Higgs 2007; 2011; Lloyd 2015). The Fourth Age is frequently characterized by a combination of advanced chronological age and immobility, frailty, and lack of independence. Yet as Liz Lloyd notes, "these characteristics are rarely straightforward, are not biologically or temporally determined, and vary in how they are interpreted by older people and those around them" (Lloyd 2015, 261). This study included individuals who self-identified as "old" before the societal marker of 65, and "elderly" in their sixties and seventies (Finlay 2018). The ethnographic sessions produced distinct positionings of knowledge and ways of being in the world. Stories told during research sessions were not regarded simply as means of mirroring the world, but as the means through which it is constructed, understood, and acted upon (Crang and Cook 1995). The ethnographic method was not an attempt to draw broad conclusions from a detached vantage point. Rather, intimate and largely taken-for-granted elements of older people's everyday lives came to the forefront. Participants were not "typical" or "representative," but instead they provided an immense depth and quality of information from their distinct positionalities and contexts.

Regarding ethical concerns, there were limitations to the extent that I (a young, ablebodied, able-minded individual) could personally relate to participants. I was aware of power imbalances between participants and me through factors such as race, income, education, and age. I remained actively concerned about social relationships during the sessions and endeavored to reduce potential negative effects through positive rapport, open and honest communication, and respect. Instead of denying any power imbalance, I openly discussed it with participants and reflected upon it in my fieldnotes. Participants took advantage of my positioning: I provided information, rides, and helped with tasks whenever possible. I felt immense responsibility to represent my participants appropriately in accounts produced. Together we brainstormed about how my research and future efforts might benefit them and their peers, such as communicating findings to key stakeholders, advocating for social justice to decisionmakers, and distributing resources to local community members.

All participants openly identified as gender-conforming, heterosexual individuals. In the sessions, participants were at times uncomfortable or unwilling to discuss contentious topics such as racism, class, sex, and intimacy. This was in part affected by the varying levels of contact that I had with participants. For some it was frequent calls, emails, and visits with open and deep dialogue; for others it was a monthly appointment. Christina and June chose to end their participation early in the course of ethnographic sessions. It was difficult to reach Frank whose phone was periodically disconnected. When hospitalized during the course of our sessions, he did not want me to visit him in the hospital. Twelve months was a relatively limited period to capture experiences and perspectives of aging over time, given that it is a life stage that can span multiple decades. This project represents a starting point for more extensive and expansive research with diverse older adults and contexts of aging. 


\section{Situating Later Life: Emplacement in Action}

Each of the following sections includes vignettes from one participant to demonstrate the utility of an emplaced, feminist approach to aging. Starting from the intimate scale and site of the body, the first section examines the co-constitutive relationship between body and place in later life. The reciprocal roles of both escalate, in which older adults are more sensitive to the intensities of their aging bodies and surrounding ecologies. The second section considers present-day experiences of aging predicated upon a historicity of place-events. The third section broadens awareness of power hierarchies anchored through environments as older adults inhabit intersecting identities and navigate multiple sociospatial oppressions. Analyses in the fourth section challenge bodily privilege built into urban landscapes and enrich understanding of structural spatial inequalities facing older adults. The fifth section coalesces a relational, context-sensitive, vibrant understanding of later life. Altogether, attending to the intimate situated perspectives and experiences of older adults through the theory of emplacement extends feminist theorization of the body, space, and time. The spatiotemporal lens generates valuable new insights into the events, materialities, and places of everyday life.

\section{Denise (72 years old): Intertwining Body and Place}

Denise awoke after back surgery to bright fluorescent lights overhead with her children strewn around the hospital room. They huddled in when she stirred, anxiously peering over the hospital bed bars. Denise's sense of time felt fuzzy... something was wrong. When she got up to use the bathroom, (whop!), Denise walked right into the door frame. When a nurse brought her a tray of food, Denise looked up expectantly and waited. "Could I have cutlery please?" she asked. Her daughter worriedly replied, "Mom, can't you see the fork and knife? They're right beside your plate." Denise looked down, but all she could see was the plate of food. She could not see the cutlery-or even her left arm. Denise began to panic.

Many of my conversations with Denise revolved around vivid memories of the stroke eight years ago, an event that irrevocably changed her life. I wrote the above narrative in my fieldnotes at Denise's request to record her story. After working right up to the day of her surgery, Denise was forced to move into a nursing home at 64 to receive care and physical therapy. "Left neglect" after the stroke caused her to be unaware of her body, things, and people on the left side. Denise was unexpectedly unable to return to work and she could not drive. She repeatedly stressed that her experience of aging was not what she anticipated: "My life isn't what I pictured it was going to be (chuckling). When I was younger. . . I didn't realize my body was going to fall apart like it did." Denise felt trapped in her own body.

Old age is a period in life when the body biologically and culturally plays a pivotal role. At the biological level, Denise experienced notable bodily changes: her skin became less elastic and more wrinkled, hair greyed and thinned, joints ached, hearing and vision declined, metabolism slowed, memory declined, and sleep became more difficult. Physical manifestations of these bodily changes marked Denise as "old" to herself and others. This fundamentally affected her interactions in public life and engagement with the world around her. Denise noted some positive changes, such as doors held open, offers of assistance when grocery shopping, and opportunities for senior discounts. She also mentioned less positive experiences of ageism, including being ignored 
in public spaces. When spending time with Denise's friends and neighbors, I fielded numerous comments about the attention that I "must receive as a young woman." Some lamented that they were no longer the target of catcalls or appreciative glances and instructed me to "enjoy the beauty of youth while it lasts." Daily experiences of being old in both public and private environments revolved around their bodies and perceptions of external appearances.

The aging body is a pivotal site and scale of spatiotemporal analysis: an entity through which identities are constituted, acted upon, "fixed," and maintained (Dyck 1998). There is a weighty materiality to aging bodies-physiological changes in skin elasticity, bone structure, musculoskeletal strength, cognitive function, and sexual drive, to name a few-that influence and are influenced by both physical processes and social discourses of the surrounding environment. Geography underpins Margaret Lock's concept of local biologies in her groundbreaking work on menopause in Japan and North America (Lock 1993). She argues that differential experiences between women in each country result from a mixture of diet, cultural norms, and social relationships. Abigail Neely observes that Lock's combined approach to menopause as biological, social, cultural, and political emphasizes that nature and culture in human health are inseparable (Neely 2015). Further, bodily processes reflect the very different social and physical conditions in which people live and die.

Denise's body produced disruptions and uncertainties in navigating daily life after the stroke. She was frustrated at having "no freedom" because she could not engage in many recreational or social activities. In addition to being unable to drive or walk, Denise could not afford to use taxis. Financial deprivation exacerbated her lack of mobility and independence. An important place in Denise's life was her old nursing home's pool. She had previously resided in this complex after her stroke to recover. She had enjoyed living there and wanted to reside in the assisted living portion but could not afford to do so. After moving into her subsidized apartment, Denise tried to go back to the complex at least four times per week to use its pool. Water exercise was the only activity she could do without hurting her back. She contentedly submerged herself in the warm water and socialized with friends during one excursion together.

I observed how joyful Denise was in the water when her pain diminished. Denise was alight: laughing, chatting, and buoyant. Immersing herself in the pool for exercise, temporary cessation of pain, and socializing with friends constituted an important therapeutic experience for Denise. These excursions cost a lot on her limited income (the bus trips each way and monthly pool dues are a significant portion of her budget)-but she feels it's worth prioritizing given the physical, mental, and social health benefits.

The women walked back and forth in the water and performed exercises on the wall. They checked in with one another, such as noting the absence of other regulars and making a point to call and check in. They supported one another through health issues and personal struggles. The water was an intimately immersive therapeutic landscape that minimized bodily frustrations (Finlay et al. 2015). The intensity of these recurring place-events (Pink 2011) - the coming together of friends and immersion in warm water-transformed Denise. Pains and physical disability diminished, and the social environment enabled opportunities for conversation, laughter, and mutual support. Denise navigated her recovery and sought well-being through the human and nonhuman elements of this pivotal place (Fullagar and O'Brien 2018). 
Maurice Merleau-Ponty observed that the "body is our general medium for having a world" (Merleau-Ponty 1962, 146). It is the starting point for everyday navigations of space and place. Denise perceived that her world collapsed after the stroke. She had to relearn how to use spaces that ceased to be amenable to her new needs and abilities. Geographical challenges were exacerbated by lack of resources. Denise faced a spatial mismatch when she was unable to afford continuing to live in a care facility. Her subsidized apartment did not meet her needs: she could not reach items in the kitchen, could not use the low bathtub safely, and experienced frequent mishaps due to left neglect. Denise altered and adapted the environment as much as possible to fit her physical and emotional needs, in line with Paul Baltes's theory of selection, optimization, and compensation (Baltes 1997). Denise shaped her home to meet her bodily abilities, such as placing all food and dishes on accessible low shelving units added to her kitchen. Her "control center" was a comfortable reclining chair: the central pivot point in her living room from which she could reach her books, knitting, phone, television remote, pile of mail, and to look out the window. Denise organized and maximized limited space inside her small apartment, in addition to outside resources and community connections. She navigated around her lack of mobility in Eden Prairie's low-density suburban environment, such as ordering books through the library's home-mail system and becoming an expert on assisted mobility transit. Denise modified her living space and daily routines to maximize comfort, connection, independence, and ability in the face of severe disability. Her experiences of distress and recovery were thus shaped through complex ecologies of people, objects, digital technologies, and space-time configurations (Pink 2011; Fullagar and O’Brien 2018).

\section{Thomas (67 years old): Emplaced Strategies to Counter Self-Narratives of Decline}

When I met with Thomas on a frigid January morning, he told me that he stays sore now and feels himself tire more easily from physical exertion. Thomas was determined, however, to help his daughter move into her new house, sand and paint each room, and arrange furniture. He lamented that in the past he could have completed these tasks without issue, but now it was more difficult. Thomas expressed sadness when considering his age-related bodily decline, but with humor and optimism tried not to dwell on it. He found workarounds, such as sitting on a stool when sanding and taking breaks after particularly tiring tasks.

There is an undeniable materiality of aging caused by physiological changes that cannot be attributed entirely to culture. As Cruikshank notes: "The vigor with which feminists have challenged the notions of biological determinism leaves us in an awkward position with aging, because this process happens in / to our bodies. The spin of social construction offers nondeterministic ways to view aging, but for nearly everyone, aging means some bodily decline" (Cruikshank 2009, 1-2). This includes Thomas, who experienced stiffening joints and decreasing energy. Yet Thomas's bodily experiences were bound up in and influenced by localized sociocultural expectations. He wanted to remain a provider for his wife and adult daughter, and proudly maintained his house and cabin (including the sprinkler system, shoveling, firewood, and maintenance). Daily life intertwined sociocultural notions of masculinity with real bodily experiences ranging from pain and fatigue to strength and vibrancy. As Liz Bondi and Damaris Rose argue, elements of identity such as gender, race, class, and sexuality "never operate aspatially but are inextricably bound up with particular spaces and places within which, and in relation to which, people live" (Bondi and Rose 2003, 232). Old age represents a 
social relation outside of individual bodies in the contexts that people inhabit (Kishore 2018).

Thomas enacted and preserved his sense of masculinity in retirement through gendered activities in strategically selected places. The woodshop was a primary site for Thomas to achieve self-care, well-being, comfort, and vitality. During our many visits together, I witnessed social bonding, purpose, and masculine identity cultivated in this site. Thomas gave me a tour of the workshop and introduced me to his buddies there. He proudly showed me their projects: cutting boards, coasters, pens, game boards, and decorative Minnesota state hangings. Thomas explained that "the guys" generally have a cycle-right now they're making items for holiday craft sales, fairs, and gifts for Christmas. This is the busiest time of their cycle. After that, they tend to make items more for themselves (though, as Thomas pointed out, "there's only so many things you can make for yourself!"). The "guys" aren't making much of a profit from their wares-they've calculated that they earn $\$ 1$ per hour. It's more about the fulfilling activity and companionship with one another.

I witnessed Thomas's core group of men who spent their weekdays in the woodshop. They socialized as they worked and visibly enjoyed the tasks at hand. Only a few had professional trades experience: these were the "experts" who provided advice and help in difficult situations. The rest were retired teachers, dentists, retailers, and businessmen. On each visit, the men excitedly showed me their projects. Several took turns teaching me introductory woodworking techniques and set me to work on basic tasks such as sanding, polishing, and staining. Once I exhibited enough awareness and precision in the woodshop, Thomas and his friends set me up with the most elementary of projects: making wood pens. They also helped me sand and stain a wood project, during which they good-naturedly tried to outdo one another regarding the best stain and lacquer product. Thomas and the other men enjoyed the attention and opportunities to demonstrate their knowledge and expertise. The visits were distinct but related place-events with specific configurations of people, conversations, and activities.

The woodshop was a comforting space for "the guys" to positively navigate sociobiological understandings of aging (Lock 1993): finding ways to be comfortable with their shifting bodies and societal roles. They were able to focus on aging in terms of productivity (through the physical acts of building wood products) and companionability (in sharing these experiences with one another). The group of men cultivated purpose and routine, and navigated around age-related physical challenges by picking tasks within their abilities and asking one another for help. Thomas reflected that this was the second-best time of his life (after college), given these new relationships and fulfilling activities anchored in this place. His experiences of being an older man were inextricably tied to this micro-environment and attendant cultural, political, economic, and social expectations.

People are shaped by complex interrelationships among the body, mind, and environment (Howes 2005; Polkinghorne, Given, and Carlson 2017). Where and how we live, work, socialize, eat, recreate, and generally engage in everyday life has manifest impacts upon our bodies and minds from birth to death (Lock 1993; Neely 2015). Thomas's articulations of excitement, affection, pride, and comfort were mediated by his lifelong positionality as a heterosexual, resourced, white male. Thomas benefited from accumulated years of easy access to fresh foods, adequate and appropriate healthcare, comfortable housing, steady education and employment, and financial stability. He had not experienced longstanding struggles with sexism, racism, or 
classism. Altogether, he entered retirement in fairly good health as an able-bodied and able-minded individual. Thomas had the personal finances and broader structural supports to pursue the retirement lifestyle of his choice. This included a comfortable home environment with speedy municipal snow-plowing, well-maintained roads, abundant services, and nearby opportunities for recreation. A support system of family, friends, neighbors, and doctors generated physical, emotional, and social benefits. He had access to sites such as the woodshop where he could self-identify as strong and industrious.

The theoretical lens of emplacement stimulates inquiry into spatiotemporal underpinnings of experiences, attitudes, opinions, and perceptions (Luusua, Pihlajaniemi, and Ylipulli 2016). Embodiment brings needed attention to the body, but emplacement broadens our gaze to the role of place over time in people's identities and experiences. In this case, Thomas took pleasure in the woodshop through his capacity to enter and inhabit the space with ease. He enjoyed a strong sense of belonging and ownership. This empowerment was based upon an accumulation of place-events over his lifespan as a resourced and advantaged white male. Thomas recognized his positioning and acknowledged that his experiences would be quite different from those of socioeconomically marginalized older adults. The next section turns to Christina, who did not occupy the same sociospatial configuration of privilege. In contrast to Thomas, who felt at ease and in control of daily life contexts, Christina articulated negative experiences of displacement (Fullagar and O'Brien 2018) for herself and others aging around her.

\section{Christina (78 years old): Precarious Lives in Perilous Places}

"From slavery to the caste system, we need to figure this all out. I believe that we are all from the same source. Unfortunately, in many societies, the darker the skin the lower the caste. We need to recognize that we're all human." (Christina)

In the bathroom section of a hardware store, Christina provided her abbreviated life history. She grew up in a segregated southern state. Christina did not acknowledge a racial identity until later in life because as a child she was completely surrounded and sheltered by other black people-teachers, doctors, store owners, family, and friends. Christina instead identified as poor and working-class. It was not until young adulthood when Christina first read a book about slavery (she was not taught about it in school) that she came to grasp the deep-rooted strength of racial discrimination in the United States.

Christina was perceptively aware of differential privilege systems and overlapping matrices of power relations that influenced her experiences and opportunities. As an African American woman living in an impoverished inner-city area, she narrated struggles endured over the years including racial policing, neglect of low-income individuals, and biased social programs. She described the police's longstanding lack of interest in tackling crime or preserving safety in her neighborhood. When the police did intervene, she felt that black people could be unfairly and poorly treated. This included unfounded blame and arrests (particularly of young men), extended pretrial incarceration, and unequal sentencing applied by the judicial system. Christina described the lessons she instilled in her children and grandchildren at a young age because of their race, such as always asking for a bag to carry purchases out of the store to avoid being harassed by security guards or the police for shoplifting. Feeling alone, fearful, 
exhausted, uncertain, and angry underlined a sense of displacement (Fullagar and O’Brien 2018).

Christina spoke at length about her experiences of being "out of place" and vulnerable as an old black woman. She drew attention to the fact that age, as a systemic condition, is notably absent from most lists of intersecting inequalities. This is curious because, as Meika Loe notes:

[Age] is not all that different from gender, race, and class. Age organizes our lives and stratifies our society. The one difference is that it is temporal. We all pass through the privileges and disadvantages associated with aging; we all get old. How we experience age-based privileges or disadvantages varies, based on other aspects of our social location, and how well we actively "do age" in accordance with social norms. (Loe 2012, 18-19)

Age overlaps and intertwines with social categories and markers of difference to operate as an organizing principle of power and space. In carceral nursing homes, for example, elderly inhabitants are regulated and disciplined. In public spaces, older adults may try to hide signs of frailty or disability (Finlay 2018). Christina was experiencing newfound challenges related to her aging body, such as being unable to accomplish necessary home modifications and feeling vulnerable after several break-ins. Christina increasingly relied on her children for support. Her daughter, for example, began accompanying her to medical appointments to help process information, fully hear answers, and ask questions. Christina recounted: "I still think I'm 20-not agewise, but energy-wise. [Supportive family], I think, is something that I wonder how many other seniors have. How many seniors have someone who can take off work, or someone who is just available to them? That's going to be very, very important to me as I go through life."

Christina relied upon a strong familial support system to help with declining functional abilities and memory loss. Given a lifetime of advocating for herself, Christina was proud of her ability to vocalize her needs and ask for help. She had served on multiple community boards and organizations, led neighborhood block safety programs, and navigated social services for herself and others. She felt confident calling agencies and service providers directly to probe for further information, point out gaps and failures in their systems, and secure her needs. Some of this confidence had diminished recently due to hearing loss and feared cognitive impairments, so she increasingly relied on her children and extended support networks.

As Christina and I became comfortable with each other, I increasingly helped her myself with household tasks. I reset the thermostat when she could not understand the digital system, dragged rugs and moved furniture when she could not bend over, and grabbed dishes that she could not reach. Christina also took advantage of my resources and knowledge. I emailed her relevant materials after our conversations, provided contact information and brochures for service organizations, and promised to communicate findings to civic leaders. This was Christina's main motivation for participating in the ethnographic sessions: "You're respectful, kind, and doing important work. You're not taking advantage of anyone-you're listening to and helping us. I wish more people would listen... . There is a strong want and need for policymakers to understand seniors. Many studies do not include low-income and people of color. I am both. I want to have a voice." 
Christina was concerned about older individuals who do not know how to speak up or do not have the confidence to advocate for themselves. She felt frustrated by the lack of social services, advocacy groups, and formal structures and spaces to support marginalized older adults. She worried about herself and others becoming "stuck" at home and in precarious places.

When Christina volunteered for the board of a nearby senior high-rise, she felt it was "the saddest place [she'd] ever seen in [her] life." She noted a complete lack of services: the residents were forgotten. The majority of residents were black, and structural racism combined with ageism concentrated in this space meant that no one provided necessary services or consulted with residents to ascertain and meet their needs. Christina stressed: "They don't know how to speak for themselves, they don't know how to advocate for themselves." The building was not just a spatial container for human activity (Alidoust, Bosman, and Holden, 2018); it symbolized societal abandonment of socioeconomically marginalized older adults. Christina pushed me to use my research to challenge the treatment of older people, which overlaps with gender, race, class, and other factors to maintain and perpetuate exclusion, invisibility, and domination (Irni 2010). Christina wanted not only her story to be voiced, but broader stories of older individuals experiencing intersecting patterns of inequality, exclusion, and displacement to the literal periphery of society.

\section{Frank (77 years old): Navigating Landscape Privilege}

Urban landscapes concretize and perpetuate privilege and domination. Able bodies (Gleeson 1999), monied bodies (Mitchell 2000), and youthful bodies are expected to move through spaces at a synchronous speed. This top-down control accommodates those who meet able-bodied and able-minded norms (for example, someone able to rapidly cross a street, comfortably inhabit a multi-story mortgage-free house, and drive to the grocery store). Maurizio Antoninetti labeled these "Peter Pan neighborhoods": built for young people who will never age, will never face unexpected disabilities or economic downturns, will always be able to count on substantial affluence and valid driver's licenses, and will always act according to standardized habitudinal lifestyles for which most residential neighborhoods have traditionally been built (Antoninetti 2007, 37).

I witnessed firsthand the challenges and diminishment of those who could not meet normative environmental expectations. Frank lived in a low-income, subsidized highrise near the edge of the downtown. Despite living in a high-density urban environment, he struggled to traverse the downtown for medical appointments, meal programs, socializing, and employment. Frank worked night shifts out of economic necessity despite declining health: he talked at length about his custodial job at [the arena], which he has had part-time for twenty-five years. Frank gets paid $\$ 12.92 /$ hour. He works after events to clean bathrooms and the arena. His employers don't give him as many hours as he'd like (only four-hour night shifts a few times a week after events). Frank would like to work more than twelve hours per week because he needs the money "to pay the lights and phone." He doesn't mind cleaning the bathrooms, though it is getting harder to sweep the steps given vertigo and balance problems. Frank doesn't want to cause any complaints because of his age. He told me that they generally don't want older workers. He prefers to work alone so he can't be criticized for being slow.

Frank was fearful of losing his job. His precarious employment and living situation made him feel anxious and powerless. Frank endured extreme financial strain, 
expanding physical and cognitive disabilities, and was hospitalized three times during data-collection for food poisoning and surgeries. Frank ate a sporadic and highly varied diet based upon what free foods he could secure and the minimal items he could afford to buy in the store. This led to an inconsistent and unnutritious diet that caused gastrointestinal issues, as well as food poisoning when he ate foods stored well past their expiration dates. When I spoke to him about the hospitalizations and surgeries, he was most concerned about missing work and being physically unable to travel to churches and charities daily for free meals.

Frank felt like a "second-class citizen" whose needs were unmet. Specific concerns included icy and unplowed sidewalks unnavigable in winter, a limited bus network (including lack of signage and explanation when buses were rerouted for construction), and inadequate security for low-income older adults. He felt vulnerable to crime given his inability to defend himself or run away, and had been followed and "roughed up" several times on the way home from work. When I walked with him, he frequently commented on how enjoyable it was to have someone else for company and safety, in stark contrast to most of his commuting spent feeling vulnerable and alone.

Frank's main site of refuge was a local senior center. Frank walked there every weekday to take advantage of the free coffee and cookies, socialize with peers, check in with the center staff, and enjoy a safe and supportive atmosphere. One fall morning I walked with Frank to the senior center as he carried a bouquet of flowers: When I asked what the flowers were for as we walked, Frank replied: "Oh! They're for you or Sandra!" Sandra is the social worker who runs the [senior center]. He then handed the bouquet over to me. He explained that once every two months a local shop donates old bouquets to his building. He grabbed the best bouquet (that is, least wilted) this morning. When we arrived at the senior center, the front desk staff volunteer warmly greeted us, and Sandra came out from her cubicle to say hello. Frank proudly gave her the flowers, which she put in a vase on the front counter.

The senior center was a unique place where Frank shed feelings of loneliness and vulnerability, and instead felt secure, accepted, and comfortable. It was a vital space for Frank and other local older adults, particularly those living in nearby subsidized apartments and homeless shelters (Finlay et al. 2019; Finlay, Gaugler, and Kane 2020). Since the time of data collection, the center has closed due to lack of funding. The closure may have had disastrous consequences for vulnerable older adults whose lives pivoted around this safe, comforting, and welcoming community space.

The daily crises of marginalized older people generally go unnoticed (Klinenberg 2002). Focusing on the micro-scale of everyday public encounters and place-event interactions for older adults enriches analyses of structural inequalities and complex power operations (Valentine 2008; Doan 2010). The senior center's closure highlights the risks that marginalized older adults face. Underserved and unheard, their struggles and needs too often remain inadequately recognized by policymakers and service providers (Finlay et al. 2019). Frank did not feel comfortable or safe in the downtown environment, which generated anxieties, exclusions, and feelings of displacement (Fullagar and O’Brien 2018).

Bodies are attuned to the city just as urban practices are transformed by metropolitan bodies (Bäckström and Sand 2019). Who is empowered to occupy and manipulate certain spaces, and who is excluded (McDowell 1999)? As noted earlier, assumptions of able-bodiedness and able-mindedness permeate urban landscapes through physical features such as short-timed crosswalks, stairs and escalators, and complex transportation systems. These spatial frameworks explicitly fail to fulfill the needs of many older 
individuals, and implicitly demean the acceptability of older adults to inhabit these spaces. Those who do not match the ideal body type are not welcome. In Åsa Bäckström and Anne-Lene Sand's illustration of skateboarders' emplaced practices, study participants imagined and physically reconstructed urban environments (Bäckström and Sand 2019). Earlier we witnessed how Denise purposefully configured her home. At the broader municipal scale, Frank lacked agency to reshape his surroundings. He is representative of many older adults who feel vulnerable, insecure, and displaced in urban environments unintended for an aging population.

Pervasive societal expectations are embedded in built form in where and how aging should occur. Mobile and affluent retirees are anticipated and advertised to in urban, age-friendly communities (Finlay et al. 2019), but those in "deep old age" are rarely accommodated. The "messy business" and abjection of the Fourth Age (Gilleard and Higgs 2007; 2011; Lloyd 2015) is expected to be done in the privacy of one's home or in an institutional care environment. Nursing homes are often relegated to distal and isolated locations. Residential segregation by age remains unproblematized in scholarly literatures to date (Finlay and Finn 2020). There is an opportunity for feminists to be sensitive to underlying geographical mechanisms that exclude and marginalize older adults. By locating aging within a complex ecology of sociocultural relations, residential patterns, urban landscapes, and power structures, scholars can challenge the geographical foundations on which ageism currently rests.

\section{Emancipatory Possibilities}

This article thus far has demonstrated that aging is a universal and heterogeneous human experience that is both embodied and emplaced. Widespread contexts of ignorance and disrespect enable ageism to permeate personal perspectives, cultures, policies, and urban landscapes. The lens of emplacement reveals spatiotemporal configurations that restrict the behavior and well-being of older adults, and limit abilities to inhabit and shape surrounding spaces. Strong societal expectations keep older and younger groups in their respective places. Yet older adults are generating new communities, modes of socializing, and alternative spaces for desire, support, love, touch, comfort, solace, and interpersonal connection.

\section{June (66 years old): Center Stage}

"I've got pep in my step. I tell [my family]: there's no flies buzzin' around me. I dance." June was a funny, headstrong, and loving woman who wore edgy outfits and stylish boots. She faced bodily changes and overcame disadvantages as a low-income, African American woman. June countered long-term chronic pain and degenerative arthritis through her well-honed mantra "just keep moving." June noted: "I'm glad to be alive. There's some people who aren't as fortunate, who can't move around, who can't do things, who can't enjoy life, who can't do things that I can do." She recognized her struggles and disadvantages but refused to be a passive victim of her circumstances.

June was a central figure in her family, church, and community. She provided food and sewed blankets for those in need, distributed health information, and cared for sick family members and friends. During one session together, I witnessed June in action as a cancer society volunteer at a regional health fair. She animatedly educated individuals about symptoms, mammograms, and other cancer-screening tests. Between conversations with me and with fair-goers, June went around to the other booths to collect 
free items such as cups, sweets, magnets, and toys for her grandchildren. June repeatedly checked her loot while naming each grandchild aloud to ensure that she had enough. She explained: "We've always been poor, but rich because we have family." June grew up on the south side of Chicago and was a member of the first graduating class from a high school for underprivileged youth. She marched with Martin Luther King Jr., met Mary Daly (a radical feminist philosopher, academic, and theologian), and had her photo in Ebony magazine. June said she moved to Minneapolis to raise her boys in a "good place." She was immensely proud that all her children and grandchildren had grown into "good people."

As June aged and disability progressed, she refused to be sidelined to the literal and symbolic periphery of her family or community. June's kitchen was a constant scene of grandchildren snacking after school, children stopping in to chat and receive a container of leftovers, and extended community members seeking advice and a warm hug. June was a central figure in many people's lives and routines. She extended care and comfort to those in need.

June desired to age in her vibrant community cultivated over many years in North Minneapolis. She was stressed by the scarcity of local supportive housing options: "There's nothing for us. The areas that they want to put you in are far away." June refused to be "stuck" in a suburban high-rise far from her family and friends. She emphasized the need for older adults to have relevant health and social services nearby, and regular contact with younger people and children. June envisioned converting old North Minneapolis houses into communal senior housing dotted throughout the entire community. She described "homey, big white houses" with wide verandas out front to "watch the action." That way, June reasoned, older adults would not be a burden or hindrance on spouses, children, or other caregivers; but could maintain local connections and a sense of place (Finlay, Gaugler, and Kane 2020). "Why would you want to put seniors way out there [in the outer suburbs] when you could put 'em in a community where there are children? We need youth to make us feel younger. It's like osmosis." June vividly envisioned multigenerational communities for elders to age "in community." Through perceptive attention to her surrounding environment, June fiercely asserted her desire and intention to remain a central figure in her family and community well into old age.

\section{Ellen (73 years old): Unexpected Intimacy and Affection}

Ellen moved to Minnesota in the last five years to be closer to her only child and two grandchildren. She had only a small local network of family and friends. Ellen was thoughtful, intelligent, and articulate, and used her resources to live in a high-services downtown neighborhood close to the river, indoor and outdoor walking paths, and orchestra. Our sessions together frequently involved music, literature, and discussions of current events. Ellen checked in on me regarding my grandmother's health and my dissertation-writing progress as much as I inquired about her current and past life. In the process, we grew close.

An unexpected element of my interactions with Ellen revealed the importance of comfort, solace, touch, and intimacy. Scholars are beginning to address sexual relations and romantic intimacy in later life, but little has been done to investigate other forms of intimacy, sensual pleasure, and tactile gratification. Common stereotypes of older adults as unattractive, feeble, or sickly can make it challenging for widows and unpartnered others to receive embraces, touch, or even eye contact (Loe 2011). With emplacement 
theory's attention to the sensuous, experiencing body rooted in place (Pink 2011), the specificity and intensity of Ellen's expressive touches were evident. Places where she felt comfortable and loved, which spanned her private home to public environments, enabled intimacy and solace critical to her well-being.

Ellen was widowed and expressed loneliness. Although generally reserved, Ellen's demeanor markedly changed with her grandchildren. She was lighthearted and affectionate, as I witnessed one morning with her toddler granddaughter: I watched Olivia affectionately follow Ellen around the kitchen. She often hugged Ellen's legs and tried to peer up to watch her cooking. Olivia was curious and loving, and it was delightful to observe warm interactions between two female generations. Ellen often smiled down at her and hugged back when Olivia patted at her legs. Ellen was gentle and tender with her little granddaughter. It revealed how crucial physical touch and closeness can be, especially in later life when many older adults live alone and are at risk for social isolation (Klinenberg 2016; Finlay and Kobayashi 2018).

Ellen subtly and strategically sought out opportunities for closeness and contact. She frequented a local coffee shop during her daily walk, where she conversed familiarly with the baristas: We walked over to the [coffee shop] where Ellen got her small coffee. The staff clearly knew Ellen, and already had the coffee waiting for her by the time we got through the line to pay. They knew her regular routine and were friendly and chatty. Ellen visibly enjoyed talking to them and being social with the young barista staff. We frequently chatted with staff at the coffee shop. The manager was one of the first people Ellen became acquainted with in Minneapolis. She referred to the coffee shop with affection, as it provided warmth, care, and connection. Even with resources to afford most social and leisure activities of her choice, Ellen struggled to develop friendships and meaningful social contacts.

The human need for affection and touch is not easy to study, nor even discuss. This may contribute to gaps in the literature regarding the need for sensory gratification in later life. Loe reflects: "All too often, touch and affection get confused with sexuality, making it a difficult subject to broach, particularly among a generation encouraged to see intimacy as a private matter" (Loe 2011, 216-17). In Ellen's largely solitary life, I observed that she maximized opportunities for touch and affection in her home with grandchildren and in the familiar coffee shop. These sites provided and intensified warmth, comfort, love, and interconnection. Attention to family and nonkin relationships, and even pets and inanimate objects, sparks novel consideration of spaces that enable intimacy, comfort, solace, and interconnection.

\section{Spatializing Feminist Thought on Later Life}

Aging is complex, differentiated, and experienced in a broad range of moments and places in people's lives. It is situated within complex ecologies that shape, and are in turned shaped by, objects and things (Pink 2011). Participants brought life stories, personality, ingenuity, and meaning to their emplaced navigations of aging. Spatiotemporal experiences shaped their bodies and perspectives, such as whether participants benefited from sustained access to fresh foods, a safe home environment, supportive emergency services, and local social networks. I witnessed progressing functional limitations, health complications, and loss. However, instead of depicting participants as dependent, depressed, disabled, and victims of their surrounding circumstances, this article engages with them as agents in their homes, neighborhoods, family lives, and chosen communities. In building theory from lived experiences, this article explores diverse patterns of 
place-events that shape aging. It stimulates deeper inquiry into terrains that are generally overlooked or marked as unimportant.

Aging does not occur in a vacuum devoid of context. Just as gender, race, class, and sexuality operate spatially (Bondi and Rose 2003), so does old age. It is inextricably bound up in the spaces within which, and in relation to which, people live. Participants' bodily processes and perspectives were highly responsive to their surrounding cultural, economic, political, and built environments. The specificities and strengths of contextual pressures nested together, such as home layout, serviceprovision, racial discrimination, and interpersonal relationships, shaped distinct ways of being old. Participants embodied the very different conditions within which people live and die. The vignettes broaden "body a-where-ness" (Thrift 2008, 126) and demonstrate how spatially fixed patterns of inequality can both empower and marginalize individuals. Overlapping axes of sexism, racism, and ageism translated into consequences such as the abandonment of low-income seniors in a derelict, inner-city highrise. Through an emplaced theoretical lens, scholars can identify and address such instances of sociospatial injustice that too often occur in old age.

Feminists have acknowledged that old age is dynamic rather than a rigid or frozen identity (for example, Segal 2013). To further this notion, the lens of emplacement demonstrates how aging is part of environments in progress that are continuously reconstituted through different processes, emotions, sensations, persons, and narratives (Pink 2011). A street that is normally safe and manageable to cross, for example, may become a fearsome and/or unnavigable space when blanketed in a treacherous layer of ice (Finlay 2017). Fluctuating intensities of aching joints may alter how and when someone ventures outside the home, and how she is perceived and treated by others given the varying intensity of visible frailty and subjectivities of people around her. A home that once enshrined privacy, independence, and comfort might become a site of degrading personal care, a walled prison of social isolation, an exhausting workplace to informally care for a spouse or grandchild, or a crumbling hazardous structure (Finlay, Gaugler, and Kane 2020). Time fundamentally shifts our relations to and experiences in the multifaceted environments surrounding us that range from the micro to macro scale.

The theory of emplacement provides novel analytical and interdisciplinary opportunities to enrich understanding of bodies, space, and time in feminist philosophy. The body's biophysical materiality and sociocultural representations (Sandberg 2011; 2013) are situated within dynamic ecological contexts. Environments shape and are in turn shaped by their inhabitants, in which people express structured advantages and disadvantages of surrounding past to present contexts. Spatializing feminist scholarship enables new opportunities to identify geographically fixed patterns of injustice, marginalization, and Othering across the lifespan. Ageism transcends sexism, racism, and other axes of inequality to marginalize older populations, of whom the majority are female, given women's greater life expectancy. Applying the theoretical framework of emplacement expands understanding of the multi-scalar situations and diverse experiences of women, and stimulates new imaginations of more just configurations of people and contexts.

Acknowledgments. This study was approved by the University of Minnesota Institutional Review Board (1410P54782). The research was supported by the National Science Foundation (Award Number 1558577) and University of Minnesota's Interdisciplinary Doctoral Fellowship and Doctoral Dissertation Fellowship. I am indebted to the research study participants who so openly shared their homes, knowledge, and experiences. Thank you to mentors Susan Craddock and Abigail Neely, as well as the anonymous reviewers, who provided constructive and supportive feedback on earlier versions of the manuscript. 


\section{References}

Alidoust, Sara, Caryl Bosman, and Gordon Holden. 2018. Planning for healthy ageing: How the use of third places contributes to the social health of older populations. Ageing and Society: 1-26.

Antoninetti, Maurizio. 2007. Peter Pan will not live here anymore: A multi-approach study of the relation between neighborhood design and the ability to age in place. $\mathrm{PhD}$ diss., University of California, Santa Barbara.

Bäckström, Åsa, and Anne-Lene Sand. 2019. Imagining and making material encounters: Skateboarding, emplacement, and spatial desire. Journal of Sport and Social Issues 43 (2): 122-42.

Baltes, Paul B. 1997. On the incomplete architecture of human ontogeny: Selection, optimization, and compensation as foundation of developmental theory. American Psychologist 52 (4): 366-80.

Bondi, Liz, and Damaris Rose. 2003. Constructing gender, constructing the urban: A review of Anglo-American feminist urban geography. Gender, Place \& Culture 1c0 (3): 229-45.

Calasanti, Toni, and Kathleen Slevin, eds. 2006. Age matters: Realigning feminist thinking. New York: Routledge.

Crang, Mike, and Ian Cook. 1995. Doing ethnographies. Norwich, UK: Geobooks.

Cruikshank, Margaret. 2009. Learning to be old: Gender, culture, and aging. Lanham, Md.: Rowman \& Littlefield.

Degnen, Catherine. 2012. Ageing selves and everyday life in the North of England: Years in the making. Manchester, UK: Manchester University Press.

Doan, Petra L. 2010. The tyranny of gendered spaces: Reflections from beyond the gender dichotomy. Gender, Place \& Culture 17 (5): 635-54.

Dunn, Kevin. 2005. Interviewing. In Qualitative research methods in human geography, ed. Iain Hay. Oxford: Oxford University Press.

Dyck, I. 1998. Women with disabilities and everyday geographies: Home space and the contested body. In Putting health into place: Landscape, identity, and well-being, ed. R. Kearns and W. Gesler. Syracuse, N.Y.: University of Syracuse Press.

England, K., and I. Dyck. 2011. Managing the body work of home care. Sociology of Health and Illness 33 (2): 206-19.

Finlay, J., T. Franke, H. McKay, and J. Sims-Gould. 2015. Therapeutic landscapes and well-being in later life: Impacts of blue and green spaces for older adults. Health Place 34: 97-106.

Finlay, J. M. 2017. "Walk like a penguin": Older Minnesotans' experiences of (non)therapeutic white space. Social Science and Medicine 198 (C): 77-84.

Finlay, J. M. 2018. Cities of (In)Difference: A Mixed-Methods Analysis of Place and Wellbeing in Later Life. PhD diss., University of Minnesota.

Finlay, Jessica M., and Jay A. Bowman. 2017. Geographies on the move: A practical and theoretical approach to the mobile interview. Professional Geographer 69 (2): 263-74.

Finlay, J. M., and L. C. Kobayashi. 2018. Social isolation and loneliness in later life: A parallel convergent mixed-methods case study of older adults and their residential contexts in the Minneapolis metropolitan area, USA. Social Science and Medicine 208: 25-33.

Finlay, Jessica M., Hayley R. McCarron, Tamara L. Statz, and Rachel Zmora. 2019. A critical approach to aging in place: A case study comparison of personal and professional perspectives from the Minneapolis metropolitan area. Journal of Aging \& Social Policy: 1-25.

Finlay, Jessica M., Joseph E. Gaugler, and Robert L. Kane. 2020. Ageing in the margins: Expectations of and struggles for "a good place to grow old" among low-income older Minnesotans. Ageing and Society 40 (4): 759-83.

Finlay, Jessica M., and Finn, Brandon. 2020. Geography's blind spot: the age-old urban question. Urban Geography:1-18

Fullagar, Simone, and Wendy O'Brien. 2018. Rethinking women's experiences of depression and recovery as emplacement: Spatiality, care and gender relations in rural Australia. Journal of Rural Studies 58: 12-19.

Gilleard, Chris, and Paul Higgs. 2007. The third age and the baby boomers: Two approaches to the social structuring of later life. International Journal of Ageing and Later Life 2 (2): 13-30.

Gilleard, Chris, and Paul Higgs. 2011. Ageing abjection and embodiment in the fourth age. Journal of Aging Studies 25 (2): 135-42.

Gleeson, Brendan. 1999. Geographies of disability. New York: Routledge. 
Gullette, Margaret. 2004. Aged by culture. Chicago: University of Chicago Press.

Herron, Rachel V., and Mark W. Skinner. 2012. Farmwomen's emotional geographies of care: A view from rural Ontario. Gender, Place \& Culture 19 (2): 232-48.

Herron, R. V., and M. W. Skinner. 2013. The emotional overlay: Older person and carer perspectives on negotiating aging and care in rural Ontario. Social Science and Medicine 91: 186-93.

Hopkins, Peter, and Rachel Pain. 2007. Geographies of age: Thinking relationally. Area 39 (3): 287-94.

Howes, David, ed. 2005. Empire of the senses: The sensual culture reader. Oxford: Berg.

Ingold, Tim. 2000. The perception of the environment. London: Routledge.

Irni, Sari. 2010. Ageing apparatuses at work: Transdisciplinary negotiations of sex, age and materiality. $\mathrm{PhD}$ diss., Åbo Akademi University.

Kishore, Shweta. 2018. "Out of place" bodies and gender: Urban exclusion and emplacement as documentary method in My Own City. Feminist Media Studies 19 (5): 619-36.

Klinenberg, Eric. 2002. Heat wave: A social autopsy of disaster in Chicago. Chicago: University of Chicago Press.

Klinenberg, Eric. 2016. Social isolation, loneliness, and living alone: Identifying the risks for public health. American Journal of Public Health 106 (5): 786-87.

Lloyd, Liz. 2015. The fourth age. In Routledge handbook of cultural gerontology, ed. Julia Twigg and Wendy Martin. New York: Routledge.

Lock, Margaret M. 1993. Encounters with aging: Mythologies of menopause in Japan and North America. Berkeley: University of California Press.

Loe, Meika. 2011. Aging our way: Independent elders, interdependent lives. New York: Oxford University Press.

Luusua, Anna, Henrika Pihlajaniemi, and Johanna Ylipulli. 2016. Northern urban lights: Emplaced experiences of urban lighting as digital augmentation. In Architecture and interaction: Human computer interaction in space and place, ed. Nicholas S. Dalton, Holger Schnädelbach, Mikael Wiberg, and Tasos Varoudis. New York: Springer International.

Marshall, C., and G. Rossmann. 2016. Designing qualitative research. 6th ed. Newbury Park, Calif.: Sage.

Marshall, Leni. 2006. Aging: A feminist issue. National Women's Studies Association 18 (1): vii-xiii.

Massey, Doreen. 2005. For space. London: Sage.

McDowell, Linda. 1999. Gender, identity, and place: Understanding feminist geographies. Minneapolis: University of Minnesota Press.

Merleau-Ponty, Maurice. 1962. Phenomenology of perception. Trans. C. Smith. New York: Humanities Press.

Milligan, Christine, and Anna Tarrant. 2018. Social and cultural geographies of ageing. In Geographical gerontology: Perspectives, concepts, approaches, ed. Mark W. Skinner, Gavin J. Andrews, and Malcolm P. Cutchin. New York: Routledge.

Mitchell, Katharyne. 2000. The culture of urban space. Urban Geography 21 (5): 443-49.

Mowl, Graham, Rachel Pain, and Carol Talbot. 2000. The ageing body and the homespace. Area 32 (2): 189-97.

Neely, Abigail. 2015. Internal ecologies and the limits of local biologies: A political ecology of tuberculosis in the time of AIDS. Annals of the Association of American Geographers 105 (4): 791-805.

Patton, M. Q. 2002. Qualitative research and evaluation methods. 3rd ed. Thousand Oaks, Calif.: Sage.

Pilkey, Brent. 2013. Queering heteronormativity at home: Older gay Londoners and the negotiation of domestic materiality. Gender, Place \& Culture 21 (9): 1142-57.

Pink, Sarah. 2011. From embodiment to emplacement: Re-thinking competing bodies, senses and spatialities. Sport, Education and Society 16 (3): 343-55.

Polkinghorne, Sarah, Lisa Given, and Lauren Carlson. 2017. Interviews that attend to emplacement: The "walk-through" method. Canadian Association for Information Science Annual Conference, Toronto.

Sandberg, Linn. 2011. Getting intimate: A feminist analysis of old age, masculinity and sexuality. PhD diss., Linkoping University.

Sandberg, Linn. 2013. Affirmative old age: The ageing body and feminist theories on difference. International Journal of Ageing and Later Life 8 (1): 11-40.

Segal, Lynne. 2013. Out of time: The pleasures and the perils of ageing. London: Verso.

Tarrant, Anna. 2013. Negotiating multiple positionalities in the interview setting: Researching across gender and generational boundaries. Professional Geographer 66 (3): 493-500. 
Tarrant, Anna. 2015. The spatial and gendered politics of displaying family: Exploring material cultures in grandfathers' homes. Gender, Place \& Culture 23 (7): 969-82.

Thrift, N. 2008. Performance and performativity. In A companion to cultural geography, ed. S. Duncan, J. C. Nuala, and R. H. Schein. Malden, Mass.: Blackwell.

Twigg, Julia. 2004. The body, gender, and age: Feminist insights in social gerontology. Journal of Aging Studies 18 (1): 59-73.

Valentine, G. 2008. Living with difference: Reflections on geographies of encounter. Progress in Human Geography 32 (3): 323-37.

Woodward, Kathleen. 1999. Figuring age: Women, bodies, generations. Bloomington: Indiana University Press.

Jessica Finlay is a Postdoctoral Research Fellow in the Social Environment and Health program at the University of Michigan. Her mixed-methods research investigates the role of built, social, natural, and microbial environments for health and well-being in later life. Bridging geography and gerontology, Jessica focuses on the everyday experiences, contexts, and needs of older people. She seeks strategies to support aging in places that nurture physical, mental, and social well-being. jmfinlay@umich.edu

Cite this article: Finlay J (2021). Intimately Old: From an Embodied to Emplaced Feminist Approach to Aging. Hypatia 36, 80-100. https://doi.org/10.1017/hyp.2020.51 